\title{
Sonia Virgone, La Fée des grèves di Paul Féval. Un romanzo bretone in cerca di identità
}

Annarosa Poli

\section{(2) OpenEdition}

1 Journals

\section{Edizione digitale}

URL: http://journals.openedition.org/studifrancesi/27871

DOI: 10.4000/studifrancesi.27871

ISSN: 2421-5856

\section{Editore}

Rosenberg \& Sellier

\section{Edizione cartacea}

Data di pubblicazione: 31 décembre 2006

Paginazione: 626-627

ISSN: 0039-2944

\section{Notizia bibliografica digitale}

Annarosa Poli, « Sonia Virgone, La Fée des grèves di Paul Féval. Un romanzo bretone in cerca di identità », Studi Francesi [Online], 150 (L | III) | 2006, online dal 30 novembre 2015, consultato il 08 novembre 2020. URL : http://journals.openedition.org/studifrancesi/27871 ; DOI : https://doi.org/10.4000/ studifrancesi.27871

Questo documento è stato generato automaticamente il 8 novembre 2020.

\section{(c) $(1)$}

Studi Francesi è distribuita con Licenza Creative Commons Attribuzione - Non commerciale - Non opere derivate 4.0 Internazionale. 


\title{
Sonia Virgone, La Fée des grèves di Paul Féval. Un romanzo bretone in cerca di identità
}

\author{
Annarosa Poli
}

\section{NOTIZIA}

SONIA VIRGONE, La Fée des grèves di Paul Féval. Un romanzo bretone in cerca di identità, Università di Macerata, «Quaderni di filologia e lingue romanze», III serie, $\mathrm{n}^{\circ}$ 19, 2004, pp. 29-48

1 Come viene opportunamente ricordato da S. Virgone, Paul Féval, oggi dimenticato, fu uno dei più fecondi romanzieri popolari francesi della prima metà dell'Ottocento $\mathrm{e}$ anche uno dei più letti. Dopo aver raggiunto la notorietà con Les Mystères de Londres (Paris, 1843) tuttavia fu considerato uno scrittore di letteratura «industriale» e, privato di qualsiasi riconoscimento letterario, fino ad una rapida discesa nell'oblio. Oggi viene ricordato essenzialmente come l'autore di un'unica opera: Le Bossu (Bruxelles, 1857) che lo fece conoscere in Europa. A partire dalla seconda metà del XX secolo, la critica ha voluto riabilitare Féval e la sua produzione. La Fée des grèves viene giudicato un testo rappresentativo poiché rientra nelle categorie preferite dal romanziere in tutta la sua carriera. In quest'opera emerge la figura della Bretagna, sua patria nativa, e fonte della sua creazione. Il romanzo è stato pubblicato sulla «Gazette de France» dal 27 giugno al 23 ottobre 1850. Nel 1851 saranno pubblicate numerose edizioni in volume presso l'editore Cadot. Nel 1877, dopo la «conversion» di Féval dell'anno precedente, il romanzo verrà stampato in una nuova versione «revue et corrigée» in cui si elimineranno tutti i passi giudicati immorali o anticlericali.

2 Le opere minori del romanziere sono state lasciate in ombra. La Fée des grèves che fa parte di questa produzione, figura tra queste sue produzioni e non è mai stato preso in considerazione dalla critica. Jean-Pierre Galvan finalmente, nel 2000 (Paris, Encrage, 
«Parcours d'une œuvre», p. 13), lo definisce «roman du Mont Saint-Michel». Armelle Diveres lo giudica come esempio di romanzo storico, mentre Pierre Jakez Hélias lo considera un romanzo bretone. L'autore attribuisce al romanzo una triplice identità: storica, popolare e bretone contemporaneamente, mostrando fino a che punto riesce ad aderire alle tre definizioni. La definizione di romanzo storico può essere giustificata dal fatto che l'azione del romanzo si svolge nel 1450 nel ducato di Bretagna e riprende un episodio narrato nella Histoire de Bretagne di Lobineau. Bisogna tuttavia tener conto che dei 33 capitoli solo i primi tre e l'epilogo finale sono ispirati al racconto citato poiché il resto della storia è frutto dell' immaginazione dell'autore. Per produrre un effetto più drammatico Féval inserisce dei cambiamenti di avvenimenti e di personaggi che dimostrano l'originalità dello scrittore rispetto agli altri romanzieri storici e si inserisce a metà strada tra Walter Scott e Alexandre Dumas.

3 I personaggi storici, nei romanzi di Féval, hanno spesso delle parti secondarie e anche le loro azioni sono limitate nella loro influenza sullo sviluppo della trama romanzesca. Lo scopo fondamentale dello scrittore è quello di dipingere un quadro fedele dei costumi dell'epoca che serve a rafforzare la veridicità della sua storia. La differenza con W.Scott sta nel fatto, secondo S.Virgone, che Féval non era né un erudito né uno storico dell'ambiente, ma si prefiggeva di «faire vrai».

Come romanzo popolare La Fée des grèves possiede tutte le caratteristiche del feuilleton: divisione del racconto in episodi quotidiani, suspence alla fine di ogni puntata, colpi di scena, assenza di introspezione, azione spesso frenetica. A differenza degli scrittori di feuilleton però Féval, prima di scrivere, faceva uno schema nella sua mente nel quale determinava le funzioni dei personaggi principali e l'organizzazione dell'azione per evitare errori tipici del genere e conservare la piena libertà di prolungare o di accorciare l'azione stessa. I romanzi di Féval partivano abitualmente dalla rottura di un equilibrio che la narrazione doveva ristabilire; seguivano poi le avventure dei personaggi e il crescendo della crisi con un transitorio trionfo del male che pareva opporsi ad una conclusione felice. La sconfitta finale del male permetteva così il raggiungimento di una pace idilliaca. Dopo una successione di transizioni e miglioramenti, l'epilogo coincide con il ritorno obbligato all'ordine iniziale. Ci pare opportuno il paragone con i melodrammi di moda nella prima metà dell'ottocento, il che spiega perché Féval fu nello stesso tempo romanziere e autore drammatico. Il linguaggio di queste narrazioni è caratteristico del romanzo d'appendice: tutto è abilmente prevedibile per mezzo di anticipazioni e di «vocaboli spia» ed è evidente la coincidenza con la tecnica del romanzo popolare.

5 L'esame dettagliato della Fée des grèves da parte dell'autore tende a dimostrare la sua adesione alle formule del romanzo popolare anche se nel suo interno vi sono degli elementi caratteristici della volontà dello scrittore di allontanarsi da questo genere. L'originalità di Féval risiede nel tentativo di sovvertire l'ordine e la struttura del romanzo popolare trasgredendo ai suoi codici. Se ne può concludere che quest' opera ha le caratteristiche tipiche del romanzo d' appendice ottocentesco, ma ne è anche la parodia.

6 Viene poi messo in luce come questo romanzo abbia un'anima tipicamente bretone. Féval si fa narratore della sua terra, della sua storia, dei suoi costumi e in particolare del paesaggio in cui la natura domina selvaggia e minacciosa contro l'uomo. Prevale infatti nel romanzo l'elemento marino in cui le maree (soprattutto quelle della baia del Mont Saint-Michel) rappresentano un fenomeno affascinante, ma pericoloso. 
L'interesse per il folklore della regione è molto vivo nel ricordo di leggende, di miti, canzoni che evocano il colore locale della mitica Bretagna. Interessante è il personaggio della fata della quale Féval cerca di spiegare i poteri soprannaturali molto cari nell'immaginario bretone. L'atmosfera di questo romanzo è lirica e magica ad un tempo, tipicamente romantica per quello che è eccezionale e sensazionale. Anche se altri romanzi di Féval descrivono le terre d'Europa, America e Australia, si avverte una simpatia particolare per la sua terra nativa. Questa ricerca ci pare di particolare interesse poiché attira la nostra attenzione su un' opera dimenticata di un autore, oggi trascurato, che pur ha rappresentato un punto fermo nel romanzo popolare europeo. 